\title{
Performance assessment of VoIP service over different handover mechanisms in UMTS networks
}

\author{
Qusay Jalil Kadhim, Ali M. Alsahlany, Ahmed Hassan Hadi \\ Department of Communication Techniques Engineering, Engineering Technical College/Najaf, Al-Furat Al-Awsat \\ Technical University, Najaf, Iraq
}

\begin{abstract}
Article Info
Article history:

Received Aug 12, 2020

Revised Mar 10, 2021

Accepted Mar 21, 2021

\section{Keywords:}

Hard handover

Jitter

MOS

Soft handover

UMTS

VOIP

ABSTRACT

Many researchers have discussed various topics in universal mobile telecommunication system (UMTS) networks: the process of switching from one cell to another for the subscriber and the impact of the quality of the connection during the transition process, quality of services (QoS), the quality of the uplink and downlink carrier line, the various types of code for the voice transmitted through the Internet, especially the research that discussed voice over internet protocol (VoIP) technology as voice travels from cell to cell in mobile networks, depending on the type of delivery. In this paper, a proposed scenario of a UMTS network was implemented to evaluate the multicellular VoIP movement; the proposed UMTS network was simulated using the OPNET 14.5 simulator. The calculation and analysis of the different parameters of the user while moving from one cell to another with different movement speeds considered, the best mean opinion score (MOS) value (3.19) registered for the scenario (soft handover) comparing with another type of handover (3.00).
\end{abstract}

This is an open access article under the CC BY-SA license.

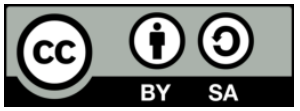

\section{Corresponding Author:}

\author{
Ali M. Alsahlany \\ Department of Communication Techniques Engineering \\ Engineering Technical College/Najaf, Al-Furat Al-Awsat Technical University \\ Najaf, Iraq \\ Email: alialsahlany@atu.edu.iq
}

\section{INTRODUCTION}

Today, the number of mobile Internet users are constantly increasing due to rapid development and spread of various wireless technologies and interoperability around the world for microwave access, many providers provide Internet service via different wireless networks [1]. Wireless networks available everywhere to connect the Internet in a stable manner at any time, the voice over internet protocol (VoIP) applications have become the most popular in many of the wireless networks everywhere, VoIP considers the next generation of mobile phones. While many users easily use VoIP connections, however, users cannot bypass wireless networks while communicating over internet protocol (IP) because different factors such as diffraction, scattering, reflection, and power restricted which caused connection instability in wireless networks.

Chacón and Edward [2] described a proposal research to study the performance of the handover on VoIP service in the universal mobile telecommunication system (UMTS) network. They focus on the effect of the handoff on the quality of receive and transmit voice. Alsahlany [3], analysis and evaluation of service quality performance to get the maximum QoS value, VoIP traffic was performed under different types of voice coding. Using the coding appropriately is very important in implementing VoIP. The results showed that the codec G.729A has an acceptable MOS value and the lowest received deviation for the transmission 
packet compared with G.711 and G.723.1. Besides that, the average delay, such as average end to end delay and audio noise, are lower in G.729A codecs with respect to other codecs indicated. Duran et al. [4] designed for both horizontal and vertical delivery of the sound quality over wireless LAN, so these factors were taken into account in the planning and dimensions of wireless and cellar convergence networks. It is illustrated how the horizontal delivery interval can have a significant impact on conversation quality, due to packet loss. The results showed that it takes a longer time for quality improvement to be seen that way due to the impact of modernity.

Munadi et al. [5], that the handover delay for the subnet scenario does not cause the call session to be interrupted, but rather stops the audio flow only within 118 milliseconds (with zero packet loss), with the delivery process completed, the call session can continue. Jakimoski and Janevski [6] conducted a study on the performance of sending voice packets during vertical transfers between 3GHSPA, WiMAX (IEEE 802.16), and Wi-Fi (IEEE 802.11). They analyzed performance metrics, such as latency, delivery, and packet loss, to obtain the effects of vertical scrolling on the performance of the mobile node. Results from UMTS to WiMAX showed that the handover delay has been severely affected by selecting time-lapse parameters on the link layer, Packet loss is also analyzed to obtain the best improvement in vertical deliveries between UMTS, WiMAX, and WLAN for VoIP traffic.

Yussuf et al. [7] compared the evaluation of hard handover performance and soft handover for the UMTS network. They simulated and analysis of UMTS handover, operations based on different QoS parameters such as uplink transmission capacity, number of active setcell, experimental channel and number of cells removed from active setcell. They discovered that soft handover supports signal continuity while moving through the geographic region.

The author of Fitzpatrick et al. [8], proposed a new mechanism for providing VoIP service over the WLAN (IEEE 802.11b) using stream control transmission protocol (SCTP). SCTP is used to permits a user connection to multiple WLAN access points. Poll packets of VoIP data at different data rates used to evaluate the quality metrics of the available networks. As it turned out, the delivery mechanism worked on WLAN networks with different data rates using three different of audio codecs. The results also showed a high relationship between the MOS value calculated by the proposed mechanism and the MOS value measured by a VoIP call in the WLAN. The researchers presented a simulation showing the delivery of SCTP endpoints between AP heterogeneous transfer rates.

Chowdhury and Gregory [9], the performance of handover in $3 \mathrm{G}$ mobile networks is compared to handover used in WiMAX technology based on Internet applications. A softer handover was found, providing the best received traffic and packet delay from one party to another by comparing three types of UMTS handover. This research focuses on the quality of VoIP communication during the movement of the user in wireless networks during the transition from one cell to the neighboring cell through a study MOS, Jitter, and the average end to end delay. This paper is focused on investigating the VoIP performance for mobile stations moving between two cells in UMTS network at different speeds with different types of handover. The rest of this paper is organized as follows: Section 2 introduces the Handover classifications. Section 3 provides our proposed network model architecture and its description. The simulation results presented in section 4. Conclusions are drawn to section 5.

\section{HANDOVER CLASSIFICATIONS}

Handover is the process that allows a user to move within a network from one cell to another, without losing the connection [10], [11]. The 802.11 standard does not specify the delivery process, but it describes the basic processes as resetting the reconnection mechanism. The reconnection process is "Nontransparent" to the user when the user moves and passes from one access point to another within the network. In the UMTS network, there are different types of handovers [12], [13].

\subsection{UMTS network handovers}

\subsubsection{Hard handover}

In this type, the old link is broken before the new link creates between the users and the radio network this process described by (hard handover), also it called a pre-made break. In cellular GSM systems where a different frequency is assigned to each cell so that hard handover is used. When the user wants to create a new link, the old link disconnected before creating a new link at a different frequency in the desired cell. Hard handover uses a simple algorithm. When the signal strength in the new cell is greater than that of the previous cell, then the mobile station uses a hard handover with a certain threshold [14], [15]. The main benefit of this type is caller uses only one channel at any instant of the time. So, in the hard handover, the phone hardware does not require to complete to receive two or more parallel channels. The main drawbacks of the hard handover are the call may be ended during the handover process [16], [17]. 


\subsubsection{Soft handover}

In this type, the channel in the source cell is held and used for a while in parallel with the channel in the target cell that is known as soft handover. CDMA technology used in UMTS. In the UMTS network, all cell has the ability to use the same frequency band and the mobile user can create connections with multiple base stations at the same time, in this type of handover, two parallel connections are created between the base stations [18]. The main benefits in the soft handover, source cell linking is broken when the reliable linking is established with the target cell. In the soft handover, the multiple cell channels are at the same time maintained, when the channels interfere then call could be failing. On the other hand, this type, need more complex hardware to continue the processing in several parallel channels. In soft handover, a single call used several parallel channels [3], [19]-[21].

\section{NETWORK MODEL DESCRIPTION}

\subsection{Simulation model}

The simulation scenario for our proposed model is shown in Figure 1. It consists of one UMTS network located inside the workspace $3000 \times 200 \mathrm{~km}^{2}$ topography. The UMTS network, including server, router, UMTS_ serving GPRS support node (SGSN), UMTS_ radio network controller (RNC) respectively, and two square neighbored cells. Each cell consists of UMTS_node_B (tower named gateway) and one mobile station. The scenario also included the application definition and profile configuration which are necessary to define an application that works in the network. The coverage area of each base station UMTS_node_B is 1.5 kilometers. Simulations were performed using OPNET modeler 14.5.

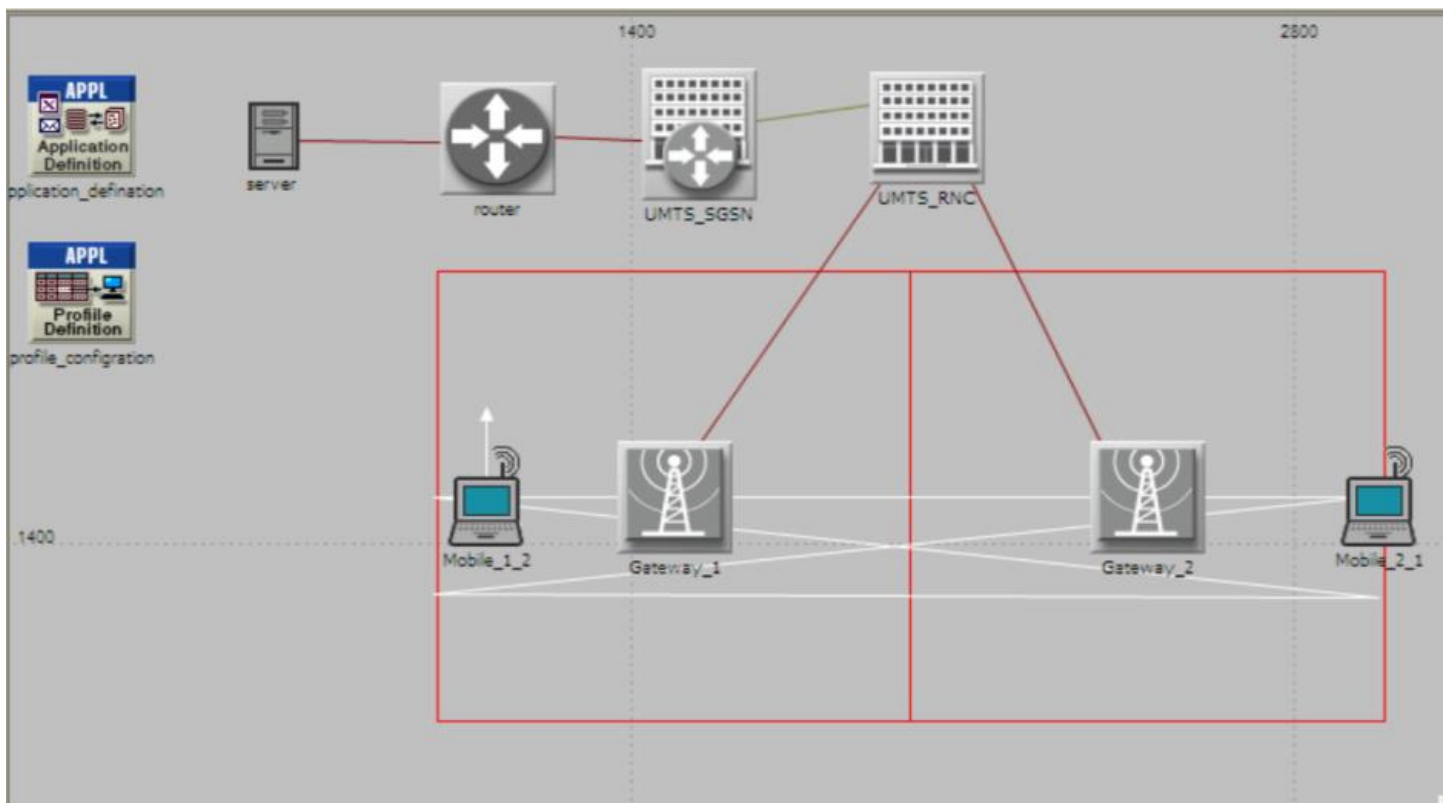

Figure 1. The proposed UMTS network structure

\subsection{Simulation parameters}

In the simulation structure shown in Figure 1 there are different parameters investigated [22]-[25]:

- The mean opinion score (MOS) in VoIP provides a numerical measure from 1 to 5 this parameter is used to evaluate the quality of human speech at the destination. Where 5 refers to the best quality while 1 refers to lower quality.

- Jitter is a technical definition that refers to the changeability over the time of the latency across a network. Latency is the time needed to transmit and receive an audio packet from source to destination. Calculating jitter value includes measuring the variation between packet delays or the packet to packet delay time in any VoIP call of online services.

- Trajectory describes the path taken by the station during movement from one point to another, in the proposed model all scenarios using the same path in different speed and different handover technology (hard and soft). 


\section{RESULTS AND DISCUSSION}

Figure 2 shows the MOS value for the mobile station (mobile 2_1) through moving from one cell to another using soft handover. In this scenario when the soft handover was enabled the mobile station to use trajectory with different speeds 30 and 40 kilometers per hour. The curve clearly showed that the MOS value of the moving mobile station at speed $30 \mathrm{k} / \mathrm{h}$ has better performance than the same station moving in $40 \mathrm{k} / \mathrm{h}$ speed. The performance comparison between soft handover and hard handover is shown in Figure 3 , The performance is investigated with respect to the jitter value (sec). In this figure the maximum jitter is recorded for hard handover with value $(0.005 \mathrm{sec})$. This scenario is investigated with two different cases, the first case mobile station moves from away the right edge of BS1 to away the left edge of BS2 and return to other point in away right edge of BS1for three times. In this case, mobile node is moved from different sectors in BS1 arriving to BS2 when the soft handover is supported. In case two, the same action is implemented with active hard handover. In both cases, mobile station was moving in $30 \mathrm{~km} / \mathrm{h}$.

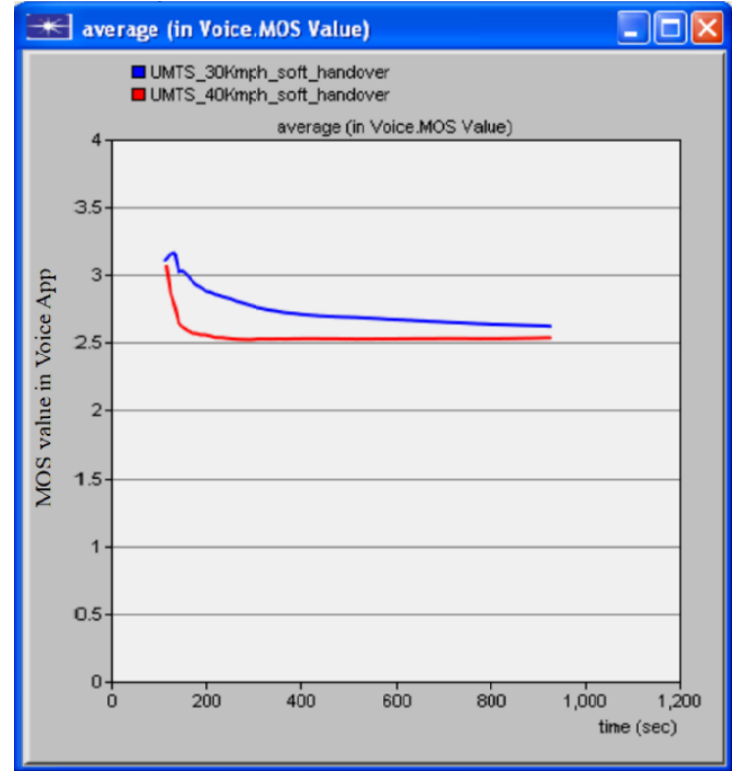

Figure 2. The mean opinion score for soft handover with different speed 30 and $40 \mathrm{~km} / \mathrm{h}$

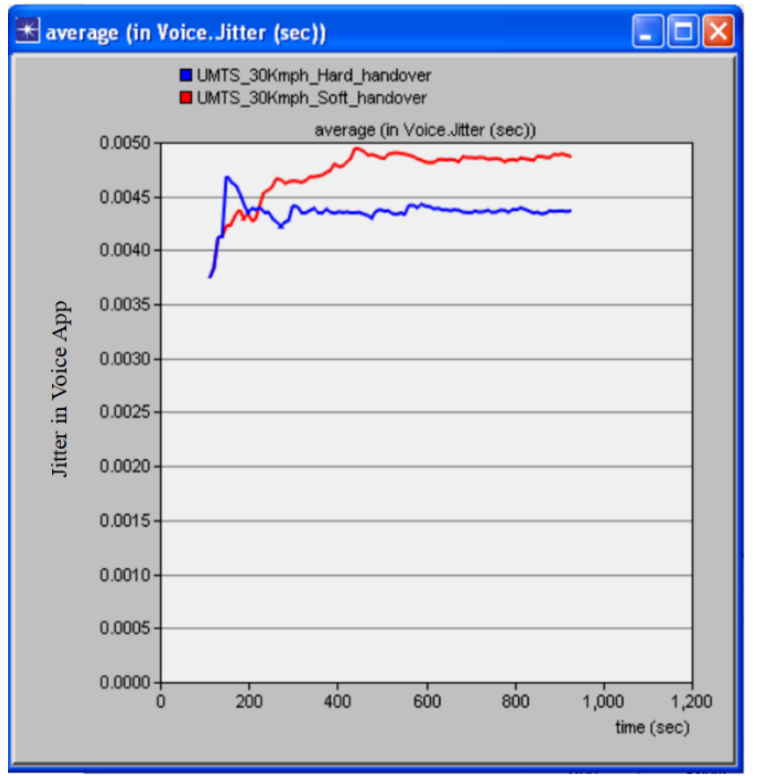

Figure 3. The jitter value in speed $30 \mathrm{~km} / \mathrm{h}$ in hard handover and soft handover 
Figure 4 describes the active setcell for the proposed simulation structure for the subscriber moving in speed $30 \mathrm{k} / \mathrm{h}$ with different handover mechanisms, the parameter active setcell during all the simulation time for the hard handover equal (1) while the active setcell in the soft handover cage between tow values 1.4 and 1.5. Figure 5 shows the average end to end delay values with respect to the simulation time. Results shows that the soft handover has the minimum end to end delay with respect to another handover. The obtained results are returned to two factors the size of transmit packet and data rate transmission. The low data rate transmission and the large size of packet transmission make the required time to process packet increase.

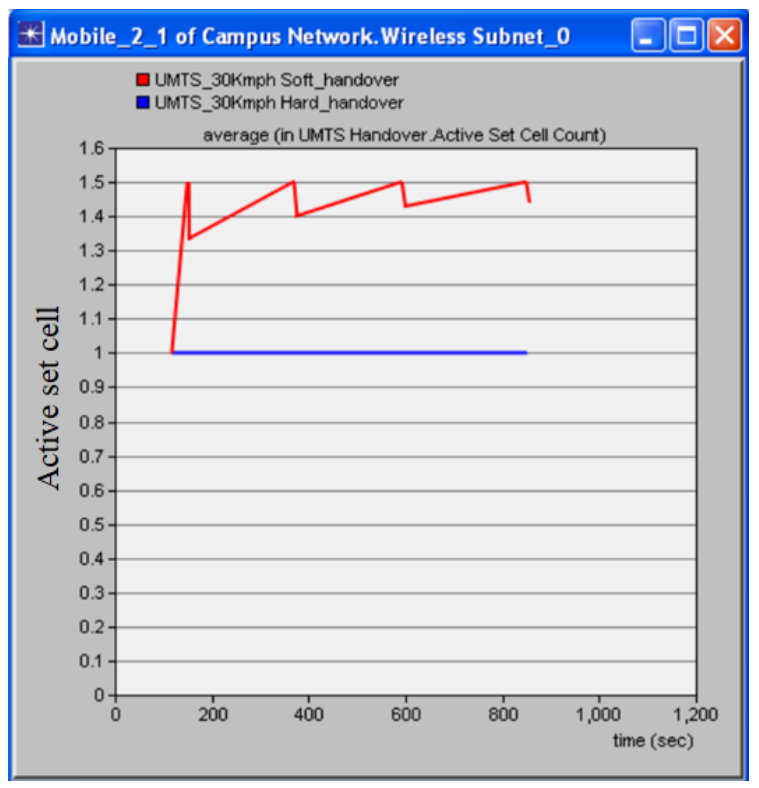

Figure 4. active setcell soft handover and hard handover

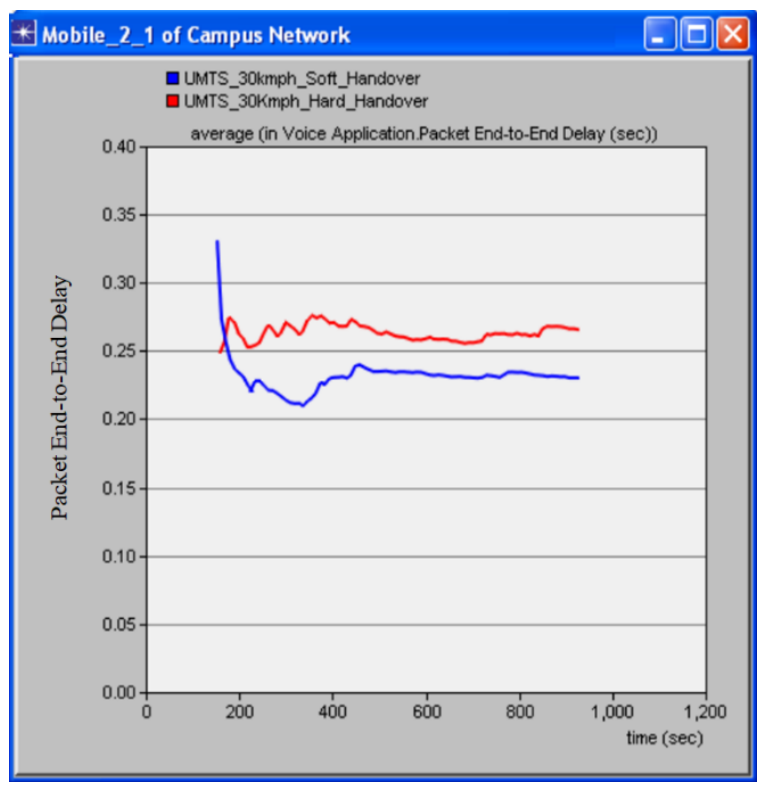

Figure 5. End to End delay for hard and soft hand over

The average sent and received voice traffic for the mobile station in speed moving $30 \mathrm{~km} / \mathrm{h}$ is shown in Figure 6. When the difference between the average sent and received traffic be small that means a network 
is more efficient. The percentage of losses of the proposed UMTS network with hard handover (0.2) is more than the percentage losses compared with the soft handover (0.13). This result explains that the noise added in the soft hand over the proposed UMTS network is less compared to the hard handover, so the soft handover is more efficient.

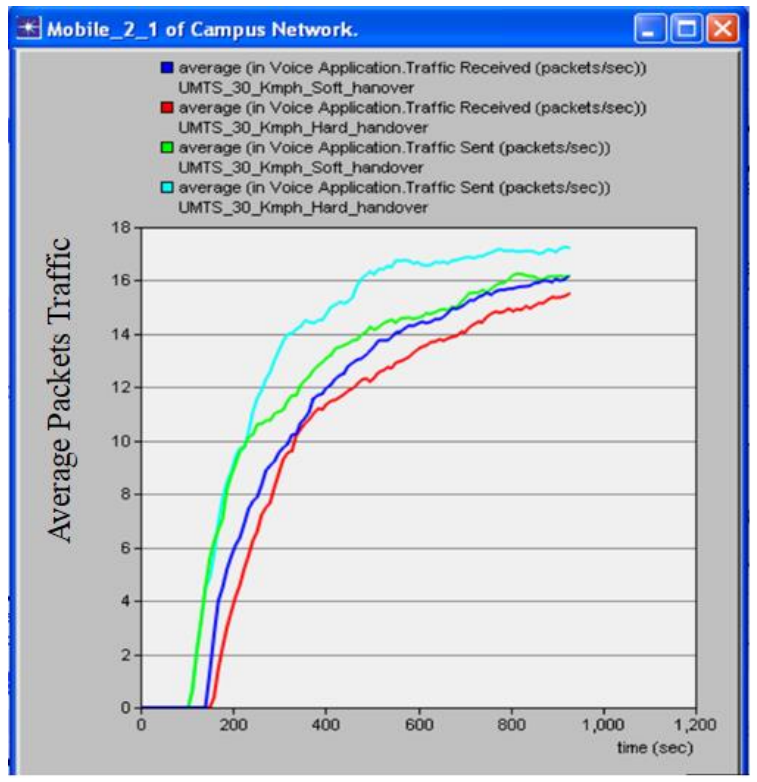

Figure 6. Average voice traffic S\&R for soft \& hard handover

\section{CONCLUSION}

The evaluation of a VoIP performance for mobile stations moving between two cells at different speeds and different handover mechanisms was performed in a different type of handover in this paper. The handover mechanism considers a very important parameter in implementing VoIP service to get the best value for the quality of service. The results showed that the type (soft handover) in a simulation gives an important result for VoIP performance, The soft handover has a satisfactory MOS value (3.19) and minimum deviation ratio received for the transmission packet compared to (Hard handover). Also, the average delay is $(0.24 \mathrm{sec})$, and minimum audio jitter value for soft handover $(0.0037)$ compared to the hard handover (0.0041).

\section{REFERENCES}

[1] S. Kashihara, M. Niswar, Y. Taenaka, K. Tsukamoto, S.Yamaguchi and Y. Oie, "Endto-End Handover Management for VoIP Communications in Ubiquitous Wireless Networks," VoIP Technologies, Shigeru Kashihara (Ed.), pp. 295-320, 2011, doi: 10.5772/14525.

[2] A. Chacón and G. Edward, "Analysis of Handover over WLAN for VoIP," Proceedings of the International Conference on Wireless Networks (ICWN), p. 1, 2011.

[3] A. M. Alsahlany, "Performance analysis of VoIP traffic over integrating Wireless LAN and WAN using different codecs," International Journal of Wireless \& Mobile Networks (IJWMN), vol. 6, no. 3, pp. 79-89, June 2014, doi: 10.5121/ijwmn.2014.6306.

[4] A. F. Duran, E. C. Del Pliego and J. I. Alonso, "Effects of handover on Voice quality in wireless convergent networks," 2007 IEEE Radio and Wireless Symposium, Long Beach, CA, USA, 2007, pp. 23-26, doi: 10.1109/RWS.2007.351780.

[5] R. Munadi, A. Mulyana, and I. H. Santoso, "Experiment Evaluation and Analysis of Delay Handover in VoIP on Campus Network," International Journal of Simulation--Systems, Science \& Technology, vol. 15, no. 4, pp. 55-60, 2014, doi: 10.5013/IJSSST.a.15.04.07.

[6] K. Jakimoski, and T. Janevski. "Analysis of Voice Over Ip During Vertical Handovers in Heterogeneous Wireless and Mobile Networks," 7-th International Conference for Informatics and Information Technology (CIIT2010), 2010, pp. 51-56.

[7] A. A. Yussuf, W. H. Hassan and S. Issa, "A review of VHD approaches in next generation wireless networks," 2012 Second International Conference on Digital Information and Communication Technology and it's Applications (DICTAP), Bangkok, Thailand, 2012, pp. 363-367, doi: 10.1109/DICTAP.2012.6215376. 
[8] J. Fitzpatrick, S. Murphy and J. Murphy, "SCTP based Handover Mechanism for VoIP over IEEE 802.11b Wireless LAN with Heterogeneous Transmission Rates," 2006 IEEE International Conference on Communications, Istanbul, Turkey, 2006, pp. 2054-2059, doi: 10.1109/ICC.2006.255072.

[9] A. S. Chowdhury and M. A. Gregory, "UMTS and WiMAX handover performance comparison," 2012 15th International Conference on Computer and Information Technology (ICCIT), Chittagong, Bangladesh, 2012, pp. 332-337, doi: 10.1109/ICCITechn.2012.6509794.

[10] G. Bhabra, S. Mackeith, P. Monteiro, and D. D. Pothier, "An experimental comparison of handover methods," The Annals of The Royal College of Surgeons of England, vol. 89, no. 3, pp. 298-300, 2007, doi: 10.1308/003588407X168352.

[11] S. Salsano, L. Veltri, G. Martiniello and A. Polidoro, "Seamless vertical handover of VoIP calls based on SIP Session Border Controllers," 2006 IEEE International Conference on Communications, Istanbul, Turkey, 2006, pp. 2040-2047, doi: 10.1109/ICC.2006.255070.

[12] K. M. Muhammad and K. M. Saad, "Handovers In 3G UMTS Traffic Classes," Diss. Blekinge Institute of Technology, (2010).

[13] A. K. Salkintzis, M. Hammer, I. Tanaka and C. Wong, "Voice call handover mechanisms in next-generation 3GPP systems," in IEEE Communications Magazine, vol. 47, no. 2, pp. 46-56, February 2009, doi: 10.1109/MCOM.2009.4785380.

[14] A. P. Markopoulou, F. A. Tobagi and M. J. Karam, "Assessment of VoIP quality over Internet backbones," Proceedings.Twenty-First Annual Joint Conference of the IEEE Computer and Communications Societies, New York, NY, USA, vol. 1, 2002, pp. 150-159, doi: 10.1109/INFCOM.2002.1019256.

[15] J. Butler, "Wireless Networking in the Developing World", eBooks 3rd Edition, 2013.

[16] N. Cranley, "Model for Wireless LAN Transmitter Location for Optimal Performance", R732133X, September 2004.

[17] T. J. G. Gómez, J. L. Abadía S., and A. F. Millán C., "Estudio de Algoritmos de Handover para Redes Inalámbricas Heterogéneas," Grupo de Investigación COMBA I+D, Consorcio I2COMMUniversidad Santiago de Cali, Cali, Valle, Colombia., 2008

[18] L.-J. Chen, T. Sun, B. Chen, V. Rajendran, and M. Gerla, "A smart decision model for vertical handoff," In Proceedings 4th ANWIRE International Workshop on WirelessInternet and Reconfigurability, Athens, Greece, 2004, pp. 1-5.

[19] A. Lakas and M. Boulmalf, "Experimental Analysis of VoIP over Wireless Local Area Networks," Journal of Communications, vol. 2, no. 4, June 2007, doi: 10.4304/jcm.2.4.3-9.

[20] A. Chacón and E. P. Guillen, "Analysis of Handover over WLAN for VoIP," in Proceedings of the International Conference on Wireless Networks (ICWN), Bogota, Colombia, 2011.

[21] A. Mishra, M. Shin, and W. Arbaugh, "An Empirical Analysis of the IEEE 802.11 MAC Layer Handoff Process," ACM SIGCOMM Computer Communication, vol. 33, no. 2, pp. 93-102, April 2003, doi: 10.1145/956981.956990.

[22] T. Szigeti, R. Barton, C. Hattingh, and K. Briley Jr., "End-to-End QoS Network Design," USA: Cisco Press. 2013.

[23] N. M. Gambhir, "Objective Measurement of Speech Quality in VOIP over Wireless LAN during Handoff," Master's Projects, San Jose State University, 2009.

[24] H. M. T. Al-Hilfi, A. H. Najim and A. M. Alsahlany, "Evaluation of WIMAX network performance of baghdad city using different audio codecs," 2017 16th RoEduNet Conference: Networking in Education and Research (RoEduNet), Targu Mures, 2017, pp. 1-5, doi: 10.1109/ROEDUNET.2017.8123762.

[25] T. M. Duong and S. Kwon, "Vertical Handover Analysis for Randomly Deployed Small Cells in Heterogeneous Networks," in IEEE Transactions on Wireless Communications, vol. 19, no. 4, pp. 2282-2292, April 2020, doi: 10.1109/TWC.2019.2963829. 